\title{
Mechanisms Governing DDK Regulation of the Initiation of DNA Replication
}

\author{
Larasati and Bernard P. Duncker* \\ Department of Biology, University of Waterloo, 200 University Avenue West, Waterloo, ON N2L3G1, Canada; \\ llarasat@uwaterloo.ca \\ * Correspondence: bduncker@uwaterloo.ca; Tel.: +1-519-888-4567 (ext. 33957) \\ Academic Editor: Eishi Noguchi \\ Received: 1 November 2016; Accepted: 16 December 2016; Published: 22 December 2016
}

\begin{abstract}
The budding yeast Dbf4-dependent kinase (DDK) complex-comprised of cell division cycle (Cdc7) kinase and its regulatory subunit dumbbell former 4 (Dbf4)-is required to trigger the initiation of DNA replication through the phosphorylation of multiple minichromosome maintenance complex subunits 2-7 (Mcm2-7). DDK is also a target of the radiation sensitive 53 (Rad53) checkpoint kinase in response to replication stress. Numerous investigations have determined mechanistic details, including the regions of Mcm2, Mcm4, and Mcm6 phosphorylated by DDK, and a number of DDK docking sites. Similarly, the way in which the Rad53 forkhead-associated 1 (FHA1) domain binds to DDK - involving both canonical and non-canonical interactions-has been elucidated. Recent work has revealed mutual promotion of DDK and synthetic lethal with dpb11-1 3 (Sld3) roles. While DDK phosphorylation of Mcm2-7 subunits facilitates their interaction with Sld3 at origins, Sld3 in turn stimulates DDK phosphorylation of Mcm2. Details of a mutually antagonistic relationship between DDK and Rap1-interacting factor 1 (Rif1) have also recently come to light. While Rif1 is able to reverse DDK-mediated Mcm2-7 complex phosphorylation by targeting the protein phosphatase glycogen 7 (Glc7) to origins, there is evidence to suggest that DDK can counteract this activity by binding to and phosphorylating Rif1.
\end{abstract}

Keywords: DNA replication; DDK; Dbf4; Cdc7; MCM; Rad53; cell cycle checkpoint; Rif1; Sld3

\section{Introduction}

In an unperturbed cell cycle, budding yeast Dbf4-dependent kinase (DDK) complex triggers the initiation of DNA replication mainly through the phosphorylation of minichromosome maintenance complex subunits 2-7 (Mcm2-7) (reviewed in [1]). When DNA damage or dNTP depletion results in checkpoint activation, the normal role of DDK is opposed by radiation sensitive 53 (Rad53) kinase, which phosphorylates DDK, leading to its dissociation from chromatin [2-6]. Recently, a much better understanding of the way in which DDK associates with both Mcm2-7 and Rad53 (structurally and functionally) has been gained. This review will focus on genetic and molecular studies that have identified and characterized the subunits of Mcm2-7 which mediate the binding of DDK, and those that are the critical targets of DDK phosphorylation. Similarly, crucial mechanistic details of both canonical and non-canonical ways in which the Rad53 forkhead-associated 1 domain (FHA1) interacts with DDK have been determined. Recently, roles for additional protein factors in regulating DDK stimulation have also been uncovered. These include synthetic lethal with dpb11-1 3 (Sld3), which both stimulates DDK phosphorylation of Mcm2 and binds to DDK-phosphorylated Mcm4 and Mcm6; and Rap1-interacting factor 1 (Rif1), which counteracts DDK activity by recruiting the protein phosphatase glycogen 7 (Glc7) to dephosphorylate Mcm4. Finally, evidence supporting a role for DDK in coordinating the initiation of DNA replication with sister chromatid cohesion will be discussed. 


\section{Insights into DDK Interactions with Mcm2-7}

One of the essential players in the initiation of eukaryotic DNA replication is the DDK complex, comprised of the serine-threonine kinase cell division cycle 7 (Cdc7), and its regulatory subunit, dumbbell former 4 (Dbf4). In the budding yeast Saccharomyces cerevisiae, each protein is encoded by a single gene, and deletion of either in a haploid strain is lethal [7]. Recently developed in vitro systems which recapitulate the molecular events culminating in origin firing have further demonstrated that the inclusion of DDK is absolutely required for the initiation of DNA replication [8-11]. The crucial function of DDK is to phosphorylate the Mcm2-7 ring, part of the larger CMG (Cdc45-Mcm2-7-go-ichi-ni-san (GINS)) replicative DNA helicase complex formed at origins of DNA replication (reviewed in [1]). The onset of these events is triggered by a rise in Dbf4 levels at the end of G1-phase, which fall after mitosis as Dbf4 is degraded in an anaphase promoting complex (APC)-dependent manner [12-15]. The high levels of active DDK at the end of G1-phase are also important for overcoming Rif1-Glc7 activity (discussed below) [16,17]. In recent years, a much higher-resolution understanding of these mechanisms has been obtained (summarized in Figure 1).

It has been known for some time that DDK is essential for DNA replication in vivo, likely due to its phosphorylation of Mcm2-7 inducing a conformational change, thereby favoring interaction with other firing factors. A P83L mutation in Mcm5 encoded by the $m c m 5-b o b 1$ allele can bypass DDK's requirement for viability, presumably mimicking a conformational change that facilitates DNA replication [18,19]. Similarly, some initial insight as to which residues of the Mcm2-7 subunits are the critical DDK targets was provided through a report that pointed to the $\mathrm{N}$-terminal serine/threonine-rich domain (NSD) of Mcm4 as being a target of DDK as well as being required for cell growth and S-phase progression [20]. To test the hypothesis that the NSD is inhibitory to the activation of origins, an allele of MCM4 lacking the NSD was transformed into temperature-sensitive $c d c 7-4$ and $d b f 4-1$ budding yeast strains and-reminiscent of $m c m 5$-bob1-found to complement the growth defects at non-permissive temperatures [21]. Further examination of the NSD revealed that it could be functionally divided into overlapping proximal (amino acids 74-174) and distal (amino acids 2-145) regions. The proximal region inhibits origin activation, as demonstrated by a comparison of wild-type $M C M 4$ and $m c m 4 \Delta 74-174$ strains. When both were exposed to the ribonucleotide reductase inhibitor hydroxyurea (HU, which synchronizes cells in early S-phase by provoking a checkpoint response), the MCM4 cells only allowed origins that are normally active in early S-phase to fire, whereas with the $m c m 4 \Delta 74-174$ strain, both early- and late-firing origins were activated. In contrast, the distal region was found to restrict the rate of replication fork progression [22,23].

$\mathrm{Mcm} 2$ has also been identified as an important DDK target, and is phosphorylated at serines 164 and 170 [24-26]. Plasmid-based expression of an allele where sequences encoding the two serines were changed to specify alanines, $m c m 2-2 A$, acted in a dominant negative fashion in an $M C M 2$ wild-type strain, resulting in severe growth defects. When the same $m c m 2-2 A$ mutant was expressed at wild-type levels from a plasmid in a temperature-activated degron (td)-tagged $\mathrm{mcm} 2$ strain at $37^{\circ} \mathrm{C}$ (a temperature at which the td-tagged Mcm2 is degraded), again severe growth defects were observed, and fluorescence-activated cell sorting (FACS) analysis revealed impaired S-phase progression. Interestingly, in both cases, the defects could be partially suppressed by the $m c m 5$-bob1 mutation [26]. Mcm2 and Mcm5 lie adjacent to one another in the Mcm2-7 ring, and disruption of the interaction between the two of them leads to an opening, which allows for loading onto double-stranded DNA [27-29]. Insight as to the possible biological role of Mcm2 modification by DDK was provided by the observation that DDK-phosphorylated $\mathrm{Mcm} 2$ dissociates from $\mathrm{Mcm} 5$ and triggers opening of the Mcm2-7 ring [26] to allow extrusion of single-stranded DNA generated from origin melting. Electron microscopy analysis of Drosophila melanogaster Mcm2-7 suggests that the Mcm2-Mcm5 gap is later sealed through the interaction of the Mcm2-7 ring with Cdc45 and GINS [30]. As is the case for Mcm2 and Mcm4, Mcm6 has an unstructured $\mathrm{N}$-terminal domain including several DDK target sites [29], and is phosphorylated by this kinase complex in vitro [31,32]. Recently, both 
DDK-phosphorylated Mcm4 and Mcm6 were shown to bind Sld3, which in turn recruits Cdc45 to origins (discussed below).

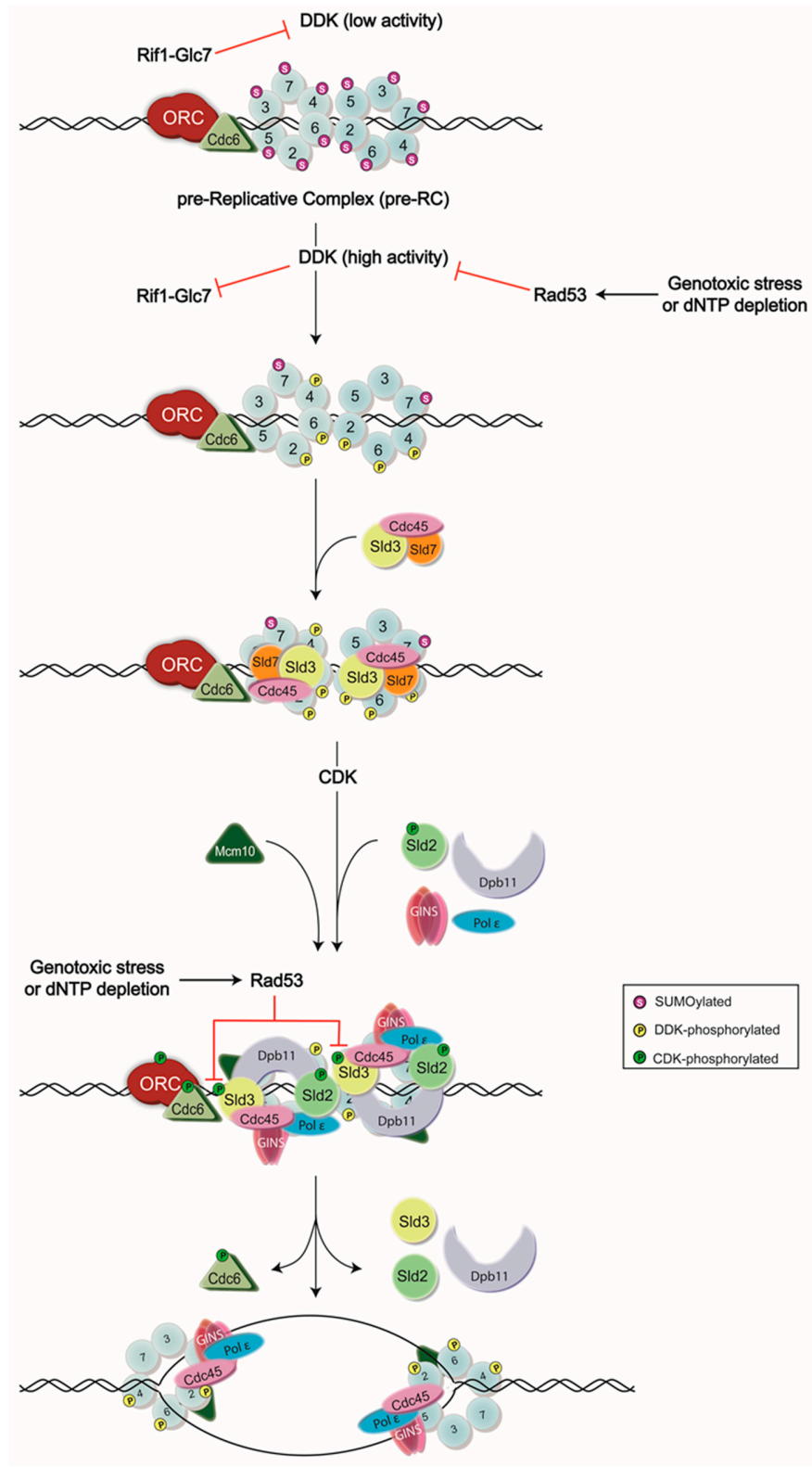

Figure 1. Model of DNA replication initiation. DNA replication is initiated by the assembly of the pre-Replicative Complex (pre-RC) at G1 phase, which is then followed by a series of phosphorylation events carried out by Dbf4-dependent kinase (DDK) and cyclin-dependent kinase (CDK) to generate the active form of the CMG (Cdc45-Mcm2-7-go-ichi-ni-san(GINS)) helicase. Normally, DDK activity is low until the end of G1 phase, as Dbf4-the regulatory subunit of DDK-is degraded in an anaphase promoting complex (APC)-dependent manner [12-15]. However, some Dbf4 that has escaped this process can provide residual DDK activity, contributing to potential premature Mcm2-7 complex phosphorylation. To avoid this, Rif1 recruits the protein phosphatase Glc7 to dephosphorylate the DDK targets. High activity of DDK in late G1 phase is proposed as a mechanism to inhibit Rif1-Glc7 activity $[16,17]$. DDK activity is also inhibited by the S-phase checkpoint kinase, Rad53, during exposure to genotoxic agents or dNTP depletion. Rad53 binds to and phosphorylates Dbf4 to remove DDK from chromatin and prevent subsequent origin firing [2-6]. Rad53 also phosphorylates an essential target of CDK, Sld3, to ensure the inhibition of DNA replication during replication stress [3,4], ORC: Origin Recognition Complex. 
In addition to characterizing the regions of MCM subunits that are phosphorylated, insight has been gained regarding the way in which the DDK complex is targeted to Mcm2-7. Sequential analysis of each MCM subunit's ability to bind the DDK components through both two-hybrid assays and co-immunoprecipitation analysis revealed that Dbf4 and Cdc7 bind to Mcm2 and Mcm4, respectively [33], and DDK docking regions have been uncovered in these two MCM subunits [20,24,33]. In the case of Mcm4, a region comprising amino acids 175-333 was found to mediate binding by DDK [20], while two different regions on $\mathrm{Mcm} 2$ are required, including amino acids 2-63 [33] and 204-278 [24]. Interestingly, while structural studies have shown that Mcm2 and Mcm4 are not in close proximity in a single Mcm2-7 hexamer, the situation is different with the double hexameric form known to be loaded onto origins of DNA replication, where these subunits lie adjacent to one another, forming a bipartite DDK binding site, consistent with the finding that the double hexamer is a preferred DDK substrate over the single hexamer [34,35]. Previous work has revealed that DDK interacts with Mcm2 through the conserved Dbf4 N- and C-motifs [36,37], however little is known about the Cdc7 region that interacts with Mcm4.

While Mcm10 does not share sequence homology with Mcm2-7 [38] and is not included in the Mcm2-7 ring, it is nevertheless indispensable for DNA replication [11,38]. A recent study showed that both DDK subunits associate with Mcm10 in vitro, with Dbf4 binding more strongly than Cdc7 [39], which is consistent with an earlier finding that Cdc23 (homolog of Mcm10 in fission yeast Schizosaccharomyces pombe) binds to Dfp1 (homolog of Dbf4 in fission yeast) [40]. Mcm10 also interacts with Mcm2-7 [38,41-44], and the strength of this interaction is increased in the presence of DDK and cyclin-dependent kinase (CDK) [45], which may facilitate double hexamer separation [46]. Moreover, Mcm10 increases DDK phosphorylation of Mcm2 [39,40] and the Mcm2-7 complex as a whole [40] in vitro.

\section{Regulation of DDK Activity by Rad53}

The ability of DDK to phosphorylate MCM subunits can be impeded by the checkpoint kinase Rad53, which is known to bind Dbf4 primarily through its FHA1 domain [47]. Under conditions where DNA is damaged or cellular dNTP pools are depleted, Dbf4 is a target of Rad53, which results in removal of the DDK complex from chromatin [2], thereby inhibiting further origin firing [3-6]. Furthermore, in vitro phosphorylation of the DDK complex by Rad53 has been found to inhibit the phosphorylation of Mcm2 by DDK [48]. Numerous Rad53 phosphorylation sites have been identified in Dbf4, and mutation of four of these to alanines in a strain for which Rad53 phosphorylation sites in Sld3 were similarly mutated resulted in late origin firing, despite exposure to HU [3]. More recently, characterization of the Dbf4 region required for binding Rad53 revealed that a stretch including amino acid residues 105-221 is both necessary and sufficient for the interaction of Dbf4 and Rad53. A crystal structure was subsequently obtained, confirming a BRCA1 C terminus (BRCT)fold, but with an additional N-terminal alpha-helix required for FHA1 binding, and was therefore designated the H-BRCT domain [49]. As FHA domains are known to bind phosphothreonine-containing motifs, each $\mathrm{H}$-BRCT threonine was systematically mutated, but none of these changes resulted in an abrogation of the interaction with FHA1. Subsequently, a combination of bioinformatics, nuclear magnetic resonance (NMR) spectroscopy, and two-hybrid analysis uncovered a non-canonical lateral surface patch on Rad53 FHA1 that binds to Dbf4 H-BRCT, distinct from its phosphothreonine epitope-binding domain [50]. Importantly, the Rad53 FHA1 domain is able to simultaneously engage Dbf4 H-BRCT and a Cdc7 phosphoepitope known to be recognized by Rad53 [50,51], suggesting a bipartite mode of interaction with the DDK complex. Indeed, this has now been confirmed through the elucidation of the crystal structure of Rad53 FHA1 simultaneously bound to Dbf4 and the phosphorylated Cdc7 peptide [52]. A requirement for FHA1 interaction with both DDK subunits may serve to simultaneously ensure that this only occurs during a checkpoint response (canonical phosphothreonine interaction with Cdc7), and exhibits substrate specificity (non-canonical interaction with Dbf4). 


\section{Mutual Promotion of Sld3 and DDK Activities}

Sld3 is a key factor in the initiation of DNA replication and represents an essential target of CDK at this point in the cell cycle [53-55]. Sld3 associates with early-firing origins in G1 phase and late-firing origins in late S-phase [56], consistent with it being one of the limiting factors that differentiate early and late origins [55,57]. It binds to both $\mathrm{Mcm} 2-7$ and Cdc45, thus serving to recruit the latter to origins [56,58]. In recruiting Cdc45, Sld3 forms a complex with Sld7 [55], which acts to reduce Sld3's affinity to Cdc45 [59], likely helping Sld3 to dissociate from the origin while Cdc45 remains and eventually moves with the replication fork as a part of the CMG helicase. GINS may also help to displace Sld3 from origins, as they compete with each other for Mcm2-7 binding [58]. Like Dbf4, Sld3 is targeted by Rad53 phosphorylation as a mechanism to inhibit origin firing in response to DNA damage [3,4].

For some time, it has been known that Sld3's association with origins of DNA replication is DDK-dependent [55,60], but the molecular mechanisms involved have been uncovered more recently. Sld3 binds to Mcm2-7 [58], which facilitates its recruitment to origins. An in vitro replication system comprised of origin DNA attached to magnetic beads supplemented with purified budding yeast replication proteins was used to show that Sld3 binds loaded Mcm2-7 in a manner dependent upon DDK [61]. Further analysis revealed that Sld3 amino acids 510-545 mediate this interaction [61]. Interestingly, this region includes many of the sites that Rad53 phosphorylates to inhibit origin firing [3], and preincubation of Sld3 with Rad53 prevented it from binding MCM in the presence of DDK [61], in much the same way as Rad53 phosphorylation prevents Sld3 from interacting with scaffold protein Dpb11 (see Figure 1) [3]. This same system was further used to examine MCM subunit binding, and revealed that Sld3 specifically interacts with DDK-phosphorylated Mcm4 and Mcm6 [61]. To test whether the binding of Sld3 to Mcm4 and Mcm6 represents the essential function of DDK, Mcm4 and Mcm6 phosphomimic mutants were generated for which N-terminal DDK-targeted serine and threonine residues were substituted with negatively charged aspartate residues (Mcm4-25D, Mcm6-25D), and were able to support roughly 60\% the wild-type level of DNA replication in the absence of DDK. Two recent studies have also reported DDK-dependent interactions between Sld3 and $\mathrm{Mcm} 2$ through pull-down, co-immunoprecipitation, and two hybrid assays [10,62]. Intriguingly, the crystal structure of Sld3 uncovered two conserved basic patches close to one another with the potential of mediating interactions with phosphorylated Mcm2-7 subunits [63]. One of these (amino acids 301-330) has been found to act as a Cdc45-binding interface [63], while mutation of the second patch for the sld3-4E mutant (K188E, R192E, K404E, K405E) resulted in disrupted interactions with $\mathrm{Mcm} 2$ and Mcm6, but not Cdc45 [62]. Importantly, a similar mutation of this region (K181E, R186E, R192E, K404E, K405E) also maintained an interaction with Cdc45, but displayed a severe growth inhibition phenotype, and this was mirrored by a failure of sld3-4E to support growth in place of the wild-type SLD3 allele [62,63]. As with $\mathrm{Mcm} 4$ and Mcm6, the N-terminus of $\mathrm{Mcm} 2$ has proven to be crucial for Sld3 binding, as Mcm2 amino acids 1-390 are sufficient for this interaction, but amino acids 1-299 are not [62]. Confirmation of the physiological importance of Sld3 interactions with the $\mathrm{Mcm} 2$ and Mcm6 N-termini, was obtained through in vivo complementation assays, in which deletion mutants with disrupted Sld3 binding for Mcm2 ( $\Delta 300-390)$ or Mcm6 ( $\Delta 1-122)$ failed to support growth or S-phase progression in the absence of wild-type $\mathrm{Mcm} 2$ or Mcm6 expression, respectively [62]. Furthermore, quantitative PCR analysis of chromatin immunoprecipitation samples (ChIP-qPCR) revealed that the mcm6 $\Delta 1-122$ mutant is deficient in recruiting both Sld3 and the single-stranded DNA binding protein replication protein A (RPA) to early-firing origin ARS607, consistent with a defect in replication initiation [62].

Interestingly, there is some evidence to suggest that-in addition to DDK facilitating the association of Sld3 with origins of DNA replication-Sld3 in turn may aid DDK in carrying out one of its roles. As mentioned above, DDK phosphorylates Mcm2 at serines 164 and 170 [24-26]. In vitro, the addition of either full-length Sld 3 or its C-terminus alone was able to substantially enhance DDK phosphorylation of Mcm2 [64]. Further evidence for the importance of this stimulatory role was 
obtained by generating a SLD3 mutant, sld3-m16 (Sld3-S556A, H557A, S558A, T559A), defective in aiding DDK with $\mathrm{Mcm} 2$ phosphorylation, but competent with respect to other functions, including binding to Dpb11, Mcm2-7, Cdc45, and T-rich single-stranded origin DNA. Reminiscent of the $m c m 2-2 A$ mutant, expression of sld3- $m 16$ resulted in a dominant-negative growth defect phenotype, and a decrease in association between Mcm2-7 and GINS was observed, pointing to a defect in CMG helicase assembly [64]. This mutually stimulatory relationship between DDK and Sld3 activities likely represents an important positive feedback loop that helps push origins past the threshold of CMG formation required for origin firing.

\section{Opposing Activities of SUMOylation, Rif1, and DDK}

Rif1 was initially identified as a regulator of telomeric length [65], but has more recently been implicated in the regulation of DNA replication in budding yeast, fission yeast, and mammalian cells [66-70]. More specifically, several lines of evidence point towards an important role for Rif1 in opposing the MCM phosphorylation activity of DDK. For example, temperature-sensitive $c d c 7-1$ cells can typically be synchronized at the G1-S boundary at $37^{\circ} \mathrm{C}$, yet failed to arrest at this temperature in a $c d c 7-1$ rif1 $\Delta$ strain [16]. Furthermore, deletion of RIF1 was found to increase the proportion of hyperphosphorylated $\mathrm{Mcm} 4$ in budding yeast whole cell extracts, as judged by slower mobility in sodium dodecyl sulfate polyacrylamide gel electrophoresis (SDS-PAGE) immunoblots $[16,17,71]$. To promote dephosphorylation, Rif1 possesses two conserved motifs for the docking of Glc7-the sole budding yeast protein phosphatase $1[16,17,71]$. Mutation of the Rif1 Glc7 docking domains was able to suppress $c d c 7-4$ and dbf4-1 growth defects, consistent with it normally reversing the MCM phosphorylation carried out by DDK [17]. Further evidence for such a role was provided by the observation that a Rif1 Glc7 docking domain mutant resulted in increased Mcm4 phosphorylation, which could be reduced or prevented altogether in a $c d c 7-1$ background at permissive and non-permissive temperatures, respectively [71]. The idea of Rif1 targeting protein phosphatases to origin-bound MCM complexes is further supported by ChIP analysis carried out in both S. cerevisiae and the fission yeast S. pombe, which showed a reduction of Glc7 and S. pombe protein phosphatase 1 Sds21 and Dis2 at late-firing origins in the absence of Rif1 or with mutation of its protein phosphatase 1-binding motifs [71].

Intriguingly, a hint of another mechanistic layer in the opposing actions of Rif1 and Dbf4 has been provided by the key finding that Dbf 4 can itself bind to Rif1 through the latter's C terminus (amino acids 1790-1916) [16,17]. It is tempting to speculate that Rif1 may thus directly counteract DDK activity, however, the ability of DDK to phosphorylate Mcm4 in vitro was not inhibited by the addition of the purified Rif1 C terminus [16]. The inverse may also be true-namely, that DDK binding and potential phosphorylation of Rif1 hinders the latter's ability to target Glc7 to origins. Indeed, putative conserved DDK and CDK phosphorylation sites are found adjacent to the protein phosphatase 1 docking domains in both S. cerevisiae and S. pombe Rif1. A S. cerevisiae Rif1 mutant for which nine of these serines were changed to alanine enhanced the temperature-sensitivity of $c d c 7-1$, while changing them to aspartic acid as a phosphomimic had the opposite effect, reminiscent of what was observed when the docking sites themselves were mutated, and equivalent results were observed with similar S. pombe mutants [16,71].

Bringing things full circle, one further role of Rif1 is to potentially counteract DDK phosphorylation of Sld3. Although it has been clearly established that Sld3 is a crucial target for CDK phosphorylation, a significant phos-tag gel mobility shift has been observed for Sld3 in G1 phase rif1 $\Delta$ cells, consistent with phosphorylation, and this shift is prevented in $c d c 7-4$ cells at non-permissive $\left(37^{\circ} \mathrm{C}\right)$ temperature [17].

Interestingly, a recent report has uncovered a potential additional mechanism for DDK-mediated promotion of MCM phosphorylation [72]. SUMOylation of chromatin-bound Mcm2-6 subunits was detected, peaking in G1 phase after MCM loading, declining during S-phase, then rising again in M phase. Mcm7 showed a slightly different pattern, with SUMOylation persisting through most 
of S-phase, before declining at the end of S-phase. SUMOylation of Mcm6 was shown to increase its interaction with Glc7 [72], promoting the dephosphorylation of Mcm2-7 [16,17,71]. When DDK was inactivated, Mcm2-6 SUMOylation was no longer lost as cells transitioned from G1 to S-phase, suggesting that DDK mediates this process. As SUMOylated forms of Mcm4 did not appear to be phosphorylated by DDK, the authors speculated that DDK might instead act on deSUMOylation enzymes, although this remains to be investigated [72].

\section{Targeting of DDK to Early Replicating Centromeric Origins of DNA Replication}

Initiation events at budding yeast origins of DNA replication are temporally regulated, with individual origins characteristically firing in early, mid, or late S-phase [73]. DDK activity is limiting for DNA replication, as Dbf4 is present at low abundance and is required throughout S-phase to promote new initiation events [57]. DDK is therefore one of the determinants of which origins fire first in S-phase; however, only recently have some of the underlying mechanistic details been uncovered. Among the earliest origins to fire in S-phase are those associated with the 16 centromeric regions of S. cerevisiae chromosomes [73]. Similar findings have been obtained with other yeast species [74-76], Trypanosoma brucei [77], and D. melanogaster [78], suggesting that this is a conserved aspect of eukaryotic cell cycles. Interestingly, live cell imaging in S. cerevisiae has revealed that both Dbf4 and Cdc7 accumulate near spindle pole bodies and kinetochores in late M and early G1 phase [79]. The centromeric localization of Dbf4 was confirmed by ChIP-qPCR for cells arrested in G1 phase, but was strongly impaired when the genes encoding either chromosome transmission fidelity 19 (Ctf19) or chromomsome loss 4 (Chl4) (both kinetochore constituents) were deleted. This effect was specific for Dbf4 association at centromeres, as Dbf4 association with early-firing origins ARS606 and ARS607 was not altered in ctf $19 \Delta$ or chl $4 \Delta$ cells. The discovery that Dbf 4 Myc-tagged at its $C$ terminus is impaired for association with centromeres, but not with replication origins allowed researchers to determine that abrogation of DDK targeting results in a specific reduction in Sld3-Sld7 origin association and a delay in replication timing at centromeric regions [79]. Importantly, the recruitment of DDK to kinetochores also appears to promote sister chromatid cohesion by targeting the sister chromatid cohesion protein 2 (Scc2)-Scc4 cohesin loader to centromeres in G1 phase, which has also been observed in Xenopus laevis [80]. Thus, DDK likely plays a central role in coordinating S-phase onset with sister chromatid cohesion. Recently, Dbf4 localization at centromeres has also been observed in human cells, and DDK was implicated in regulating the recruitment of topoisomerase 2-alpha (TOP2A), which is required for chromosome condensation and sister chromatid separation [81]. Although the timing of Dbf4 centromere association was not coincident with the onset of DNA replication, this study involved the overexpression of tagged Dbf4. Thus, it would be interesting to observe if a stronger correlation is found with normal levels of Dbf4 expression.

\section{Conclusions and Perspectives}

To initiate DNA replication, DDK binds to and phosphorylates its essential target-the Mcm2-7 ring. This phosphorylation leads to gate opening between $\mathrm{Mcm} 2$ and $\mathrm{Mcm} 5$, allowing extrusion of single stranded DNA generated by origin melting. DDK also facilitates the association of one of the essential firing factors, Sld3, with origin DNA. A key feature of this DDK-dependent recruitment is that Sld3 interacts with DDK targets Mcm2, 4, and 6. Sld3 in turn targets Cdc45 to origins, thereby facilitating the formation of the CMG replicative helicase. As many of these mechanistic details have been determined through the use of in vitro systems, the additional construction of mutant strains will be required to confirm that they hold true in vivo. The recruitment of DDK to yeast centromeric sequences in G1 phase promotes early S-phase replication of these regions, and likely ensures proper coordination with sister chromatid cohesion through Scc2-Scc4 targeting to the same loci. Similar findings in other eukaryotes merit further investigation to establish the degree of mechanistic conservation. 
Negative regulation of DNA replication by opposing DDK activity can occur via two distinct mechanisms. The checkpoint kinase Rad53 impedes DDK activity during S-phase replication stress. How Rad53 binds DDK to facilitate its phosphorylation has been characterized, exposing two FHA domain-mediated binding modes, one canonical and the other non-canonical. Rif1 and Mcm2-7 SUMOylation can each counteract DDK activity to prevent precocious DNA replication initiation in G1 phase by targeting Glc7 to dephosphorylate MCM subunits, yet exactly how Rif1 is itself recruited to origins of DNA replication, and the precise mechanism of Mcm2-7 SUMOylation, are open questions that remain to be investigated.

Acknowledgments: B.P.D. is funded by Natural Sciences and Engineering Research Council of Canada grant RGPIN 238392. L. is funded by a Lembaga Pengelola Dana Pendidikan studentship from the Indonesian Government.

Conflicts of Interest: The authors declare no conflict of interest.

\section{References}

1. Labib, K. How Do Cdc7 and Cyclin-Dependent Kinases Trigger the Initiation of Chromosome Replication in Eukaryotic Cells? Genes Dev. 2010, 24, 1208-1219. [CrossRef] [PubMed]

2. Pasero, P.; Duncker, B.P.; Schwob, E.; Gasser, S.M. A Role for the Cdc7 Kinase Regulatory Subunit Dbf4p in the Formation of Initiation-Competent Origins of Replication. Genes Dev. 1999, 13, 2159-2176. [CrossRef] [PubMed]

3. Zegerman, P.; Diffley, J.F.X. Checkpoint-Dependent Inhibition of DNA Replication Initiation by Sld3 and Dbf4 Phosphorylation. Nature 2010, 467, 474-478. [CrossRef] [PubMed]

4. Lopez-Mosqueda, J.; Maas, N.L.; Jonsson, Z.O.; DeFazio-Eli, L.G.; Wohlschlegel, J.; Toczyski, D.P. Damage-Induced Phosphorylation of Sld3 Is Important to Block Late Origin Firing. Nature 2010, 467, 479-483. [CrossRef] [PubMed]

5. Duch, A.; Palou, G.; Jonsson, Z.O.; Palou, R.; Calvo, E.; Wohlschlegel, J.; Quintana, D.G. A Dbf4 Mutant Contributes to Bypassing the Rad53-Mediated Block of Origins of Replication in Response to Genotoxic Stress. J. Biol. Chem. 2011, 286, 2486-2491. [CrossRef] [PubMed]

6. Chen, Y.-C.; Kenworthy, J.; Gabrielse, C.; Hänni, C.; Zegerman, P.; Weinreich, M. DNA Replication Checkpoint Signaling Depends on a Rad53-Dbf4 N-Terminal Interaction in Saccharomyces cerevisiae. Genetics 2013, 194, 389-401. [CrossRef] [PubMed]

7. Kitada, K.; Johnston, L.H.; Sugino, T.; Sugino, A. Temperature-Sensitive cdc7 Mutations of Saccharomyces cerevisiae Are Suppressed by the DBF4 Gene, Which Is Required for the G1/S Cell Cycle Transition. Genetics 1992, 131, 21-29. [PubMed]

8. Heller, R.C.; Kang, S.; Lam, W.M.; Chen, S.; Chan, C.S.; Bell, S.P. Eukaryotic Origin-Dependent DNA Replication In Vitro Reveals Sequential Action of DDK and S-CDK Kinases. Cell 2011, 146, 80-91. [CrossRef] [PubMed]

9. On, K.F.; Beuron, F.; Frith, D.; Snijders, A.P.; Morris, E.P.; Diffley, J.F.X. Prereplicative Complexes Assembled In Vitro Support Origin-Dependent and Independent DNA Replication. EMBO J. 2014, 33, 605-620. [CrossRef] [PubMed]

10. Herrera, M.C.; Tognetti, S.; Riera, A.; Zech, J.; Clarke, P.; Fernández-Cid, A.; Speck, C. A Reconstituted System Reveals How Activating and Inhibitory Interactions Control DDK Dependent Assembly of the Eukaryotic Replicative Helicase. Nucleic Acids Res. 2015, 43, 10238-10250. [CrossRef] [PubMed]

11. Yeeles, J.T.P.; Deegan, T.D.; Janska, A.; Early, A.; Diffley, J.F.X. Regulated Eukaryotic DNA Replication Origin Firing with Purified Proteins. Nature 2015, 519, 431-435. [CrossRef] [PubMed]

12. Cheng, L.; Collyer, T.; Hardy, C.F.J. Cell Cycle Regulation of DNA Replication Initiator Factor Dbf4p. Mol. Cell. Biol. 1999, 19, 4270-4278. [CrossRef] [PubMed]

13. Oshiro, G.; Owens, J.C.; Shellman, Y.; Sclafani, R.A.; Li, J.J. Cell Cycle Control of Cdc7p Kinase Activity through Regulation of Dbf4p Stability. Mol. Cell. Biol. 1999, 19, 4888-4896. [CrossRef] [PubMed]

14. Weinreich, M.; Stillman, B. Cdc7p-Dbf4p Kinase Binds to Chromatin during S Phase and Is Regulated by Both the APC and the RAD53 Checkpoint Pathway. EMBO J. 1999, 18, 5334-5346. [CrossRef] [PubMed] 
15. Ferreira, M.F.; Santocanale, C.; Drury, L.S.; Diffley, J.F. Dbf4p, an Essential S Phase-Promoting Factor, Is Targeted for Degradation by the Anaphase-Promoting Complex. Mol. Cell. Biol. 2000, 20, 242-248. [CrossRef] [PubMed]

16. Hiraga, S.; Alvino, G.M.; Chang, F.; Lian, H.; Sridhar, A.; Kubota, T.; Brewer, B.J.; Weinreich, M.; Raghuraman, M.K.; Donaldson, A.D. Rif1 Controls DNA Replication by Directing Protein Phosphatase 1 to Reverse Cdc7-Mediated Phosphorylation of the MCM Complex. Genes Dev. 2014, 28, 372-383. [CrossRef] [PubMed]

17. Mattarocci, S.; Shyian, M.; Lemmens, L.; Damay, P.; Altintas, D.M.; Shi, T.; Bartholomew, C.R.; Thomä, N.H.; Hardy, C.F.J.; Shore, D. Rif1 Controls DNA Replication Timing in Yeast through the PP1 Phosphatase Glc7. Cell Rep. 2014, 7, 62-69. [CrossRef] [PubMed]

18. Hardy, C.F.; Dryga, O.; Seematter, S.; Pahl, P.M.; Sclafani, R.A. mcm5/cdc46-bob1 Bypasses the Requirement for the S Phase Activator Cdc7p. Proc. Natl. Acad. Sci. USA 1997, 94, 3151-3155. [CrossRef] [PubMed]

19. Hoang, M.L.; Leon, R.P.; Pessoa-Brandao, L.; Hunt, S.; Raghuraman, M.K.; Fangman, W.L.; Brewer, B.J.; Sclafani, R.A. Structural Changes in Mcm5 Protein Bypass Cdc7-Dbf4 Function and Reduce Replication Origin Efficiency in Saccharomyces cerevisiae. Mol. Cell. Biol. 2007, 27, 7594-7602. [CrossRef] [PubMed]

20. Sheu, Y.-J.; Stillman, B. Cdc7-Dbf4 Phosphorylates MCM Proteins via a Docking Site-Mediated Mechanism to Promote S Phase Progression. Mol. Cell 2006, 24, 101-113. [CrossRef] [PubMed]

21. Sheu, Y.-J.; Stillman, B. The Dbf4-Cdc7 Kinase Promotes S Phase by Alleviating an Inhibitory Activity in Mcm4. Nature 2010, 463, 113-117. [CrossRef] [PubMed]

22. Sheu, Y.-J.; Kinney, J.B.; Lengronne, A.; Pasero, P.; Stillman, B. Domain within the Helicase Subunit Mcm4 Integrates Multiple Kinase Signals to Control DNA Replication Initiation and Fork Progression. Proc. Natl. Acad. Sci. USA 2014, 111, E1899-E1908. [CrossRef] [PubMed]

23. Sheu, Y.-J.; Kinney, J.B.; Stillman, B. Concerted Activities of Mcm4, Sld3, and Dbf4 in Control of Origin Activation and DNA Replication Fork Progression. Genome Res. 2016, 26, 315-330. [CrossRef] [PubMed]

24. Bruck, I.; Kaplan, D. Dbf4-Cdc7 Phosphorylation of Mcm2 Is Required for Cell Growth. J. Biol. Chem. 2009, 284, 28823-28831. [CrossRef] [PubMed]

25. Stead, B.E.; Brandl, C.J.; Davey, M.J. Phosphorylation of Mcm2 Modulates Mcm2-7 Activity and Affects the Cell's Response to DNA Damage. Nucleic Acids Res. 2011, 39, 6998-7008. [CrossRef] [PubMed]

26. Bruck, I.; Kaplan, D.L. The Dbf4-Cdc7 Kinase Promotes Mcm2-7 Ring Opening to Allow for Single-Stranded DNA Extrusion and Helicase Assembly. J. Biol. Chem. 2015, 290, 1210-1221. [CrossRef] [PubMed]

27. Bochman, M.L.; Schwacha, A. The Saccharomyces cerevisiae Mcm6/2 and Mcm5/3 ATPase Active Sites Contribute to the Function of the Putative Mcm2-7 "Gate". Nucleic Acids Res. 2010, 38, 6078-6088. [CrossRef] [PubMed]

28. Samel, S.A.; Fernández-Cid, A.; Sun, J.; Riera, A.; Tognetti, S.; Herrera, M.C.; Li, H.; Speck, C. A Unique DNA Entry Gate Serves for Regulated Loading of the Eukaryotic Replicative Helicase MCM2-7 onto DNA. Genes Dev. 2014, 28, 1653-1666. [CrossRef] [PubMed]

29. Li, N.; Zhai, Y.; Zhang, Y.; Li, W.; Yang, M.; Lei, J.; Tye, B.-K.; Gao, N. Structure of the Eukaryotic MCM Complex at $3.8 \AA ̊$ A . Nature 2015, 524, 186-191. [CrossRef] [PubMed]

30. Costa, A.; Ilves, I.; Tamberg, N.; Petojevic, T.; Nogales, E.; Botchan, M.R.; Berger, J.M. The Structural Basis for MCM2-7 Helicase Activation by GINS and Cdc45. Nat. Struct. Mol. Biol. 2011, 18, 471-477. [CrossRef] [PubMed]

31. Lei, M.; Kawasaki, Y.; Young, M.R.; Kihara, M.; Sugino, A.; Tye, B.K. Mcm2 Is a Target of Regulation by Cdc7-Dbf4 during the Initiation of DNA Synthesis. Genes Dev. 1997, 11, 3365-3374. [CrossRef] [PubMed]

32. Randell, J.C.W.; Fan, A.; Chan, C.; Francis, L.I.; Heller, R.C.; Galani, K.; Bell, S.P. Mec1 Is One of Multiple Kinases That Prime the Mcm2-7 Helicase for Phosphorylation by Cdc7. Mol. Cell 2010, 40, 353-363. [CrossRef] [PubMed]

33. Ramer, M.D.; Suman, E.S.; Richter, H.; Stanger, K.; Spranger, M.; Bieberstein, N.; Duncker, B.P. Dbf4 and Cdc7 Proteins Promote DNA Replication through Interactions with Distinct Mcm2-7 Protein Subunits. J. Biol. Chem. 2013, 288, 14926-14935. [CrossRef] [PubMed]

34. Francis, L.I.; Randell, J.C.W.; Takara, T.J.; Uchima, L.; Bell, S.P. Incorporation into the Prereplicative Complex Activates the Mcm2-7 Helicase for Cdc7-Dbf4 Phosphorylation. Genes Dev. 2009, 23, 643-654. [CrossRef] [PubMed] 
35. Sun, J.; Fernandez-Cid, A.; Riera, A.; Tognetti, S.; Yuan, Z.; Stillman, B.; Speck, C.; Li, H. Structural and Mechanistic Insights into Mcm2-7 Double-Hexamer Assembly and Function. Genes Dev. 2014, 28, 2291-2303. [CrossRef] [PubMed]

36. Varrin, A.E.; Prasad, A.A.; Scholz, R.-P.; Ramer, M.D.; Duncker, B.P. A Mutation in Dbf4 Motif M Impairs Interactions with DNA Replication Factors and Confers Increased Resistance to Genotoxic Agents. Mol. Cell. Biol. 2005, 25, 7494-7504. [CrossRef] [PubMed]

37. Jones, D.R.; Prasad, A.A.; Chan, P.K.; Duncker, B.P. The Dbf4 Motif C Zinc Finger Promotes DNA Replication and Mediates Resistance to Genotoxic Stress. Cell Cycle 2010, 9, 2018-2026. [CrossRef] [PubMed]

38. Merchant, A.M.; Kawasaki, Y.; Chen, Y.; Lei, M.; Tye, B.K. A Lesion in the DNA Replication Initiation Factor Mcm10 Induces Pausing of Elongation Forks through Chromosomal Replication Origins in Saccharomyces cerevisiae. Mol. Cell. Biol. 1997, 17, 3261-3271. [CrossRef] [PubMed]

39. Perez-Arnaiz, P.; Bruck, I.; Kaplan, D.L. Mcm10 Coordinates the Timely Assembly and Activation of the Replication Fork Helicase. Nucleic Acids Res. 2016, 44, 315-329. [CrossRef] [PubMed]

40. Lee, J.-K.; Seo, Y.-S.; Hurwitz, J. The Cdc23 (Mcm10) Protein Is Required for the Phosphorylation of Minichromosome Maintenance Complex by the Dfp1-Hsk1 Kinase. Proc. Natl. Acad. Sci. USA 2003, 100, 2334-2339. [CrossRef] [PubMed]

41. Homesley, L.; Lei, M.; Kawasaki, Y.; Sawyer, S.; Christensen, T.; Tye, B.K. Mcm10 and the MCM2-7 Complex Interact to Initiate DNA Synthesis and to Release Replication Factors from Origins. Genes Dev. 2000, 14, 913-926. [PubMed]

42. Izumi, M.; Yanagi, K.; Mizuno, T.; Yokoi, M.; Kawasaki, Y.; Moon, K.-Y.; Hurwitz, J.; Yatagai, F.; Hanaoka, F. The Human Homolog of Saccharomyces cerevisiae Mcm10 Interacts with Replication Factors and Dissociates from Nuclease-Resistant Nuclear Structures in G2 Phase. Nucleic Acids Res. 2000, 28, 4769-4777. [CrossRef] [PubMed]

43. Liachko, I.; Tye, B.K. Mcm10 Mediates the Interaction between DNA Replication and Silencing Machineries. Genetics 2009, 181, 379-391. [CrossRef] [PubMed]

44. Van Deursen, F.; Sengupta, S.; De Piccoli, G.; Sanchez-Diaz, A.; Labib, K. Mcm10 Associates with the Loaded DNA Helicase at Replication Origins and Defines a Novel Step in Its Activation. EMBO J. 2012, 31, 2195-2206. [CrossRef] [PubMed]

45. Douglas, M.E.; Diffley, J.F.X. Recruitment of Mcm10 to Sites of Replication Initiation Requires Direct Binding to the Minichromosome Maintenance (MCM) Complex. J. Biol. Chem. 2016, 291, 5879-5888. [CrossRef] [PubMed]

46. Quan, Y.; Xia, Y.; Liu, L.; Cui, J.; Li, Z.; Cao, Q.; Chen, X.S.; Campbell, J.L.; Lou, H. Cell-Cycle-Regulated Interaction between Mcm10 and Double Hexameric Mcm2-7 Is Required for Helicase Splitting and Activation during S Phase. Cell Rep. 2015, 13, 2576-2586. [CrossRef] [PubMed]

47. Duncker, B.P.; Shimada, K.; Tsai-Pflugfelder, M.; Pasero, P.; Gasser, S.M. An N-Terminal Domain of Dbf4p Mediates Interaction with Both Origin Recognition Complex (ORC) and Rad53p and Can Deregulate Late Origin Firing. Proc. Natl. Acad. Sci. USA 2002, 99, 16087-16092. [CrossRef] [PubMed]

48. Kihara, M.; Nakai, W.; Asano, S.; Suzuki, A.; Kitada, K.; Kawasaki, Y.; Johnston, L.H.; Sugino, A. Characterization of the Yeast Cdc7p/Dbf4p Complex Purified from Insect Cells. Its Protein Kinase Activity Is Regulated by Rad53p. J. Biol. Chem. 2000, 275, 35051-35062. [CrossRef] [PubMed]

49. Matthews, L.A.; Jones, D.R.; Prasad, A.A.; Duncker, B.P.; Guarné, A. Saccharomyces cerevisiae Dbf4 Has Unique Fold Necessary for Interaction with Rad53 Kinase. J. Biol. Chem. 2012, 287, 2378-2387. [CrossRef] [PubMed]

50. Matthews, L.A.; Selvaratnam, R.; Jones, D.R.; Akimoto, M.; McConkey, B.J.; Melacini, G.; Duncker, B.P.; Guarné, A. A Novel Non-Canonical Forkhead-Associated (FHA) Domain-Binding Interface Mediates the Interaction between Rad53 and Dbf4 Proteins. J. Biol. Chem. 2014, 289, 2589-2599. [CrossRef] [PubMed]

51. Aucher, W.; Becker, E.; Ma, E.; Miron, S.; Martel, A.; Ochsenbein, F.; Marsolier-Kergoat, M.-C.; Guerois, R. A Strategy for Interaction Site Prediction between Phospho-Binding Modules and Their Partners Identified from Proteomic Data. Mol. Cell. Proteom. 2010, 9, 2745-2759. [CrossRef] [PubMed]

52. Almawi, A.W.; Matthews, L.A.; Larasati; Myrox, P.; Boulton, S.; Lai, C.; Moraes, T.; Melacini, G.; Ghirlando, R.; Duncker, B.P.; et al. “AND” Logic Gates at Work: Crystal Structure of Rad53 Bound to Dbf4 and Cdc7. Sci. Rep. 2016, 6, 34237. [CrossRef] [PubMed]

53. Tanaka, S.; Umemori, T.; Hirai, K.; Muramatsu, S.; Kamimura, Y.; Araki, H. CDK-Dependent Phosphorylation of Sld2 and Sld3 Initiates DNA Replication in Budding Yeast. Nature 2007, 445, 328-332. [CrossRef] [PubMed] 
54. Zegerman, P.; Diffley, J.F.X. Phosphorylation of Sld2 and Sld3 by Cyclin-Dependent Kinases Promotes DNA Replication in Budding Yeast. Nature 2007, 445, 281-285. [CrossRef] [PubMed]

55. Tanaka, S.; Nakato, R.; Katou, Y.; Shirahige, K.; Araki, H. Origin Association of Sld3, Sld7, and Cdc45 Proteins Is a Key Step for Determination of Origin-Firing Timing. Curr. Biol. 2011, 21, 2055-2063. [CrossRef] [PubMed]

56. Kamimura, Y.; Tak, Y.-S.; Sugino, A.; Araki, H. Sld3, Which Interacts with Cdc45 (Sld4), Functions for Chromosomal DNA Replication in Saccharomyces cerevisiae. EMBO J. 2001, 20, 2097-2107. [CrossRef] [PubMed]

57. Mantiero, D.; Mackenzie, A.; Donaldson, A.; Zegerman, P. Limiting Replication Initiation Factors Execute the Temporal Programme of Origin Firing in Budding Yeast. EMBO J. 2011, 30, 4805-4814. [CrossRef] [PubMed]

58. Bruck, I.; Kaplan, D.L. GINS and Sld3 Compete with One Another for Mcm2-7 and Cdc45 Binding. J. Biol. Chem. 2011, 286, 14157-14167. [CrossRef] [PubMed]

59. Tanaka, T.; Umemori, T.; Endo, S.; Muramatsu, S.; Kanemaki, M.; Kamimura, Y.; Obuse, C.; Araki, H. Sld7, an Sld3-associated Protein Required for Efficient Chromosomal DNA Replication in Budding Yeast. EMBO J. 2011, 30, 2019-2030. [CrossRef] [PubMed]

60. Yabuuchi, H.; Yamada, Y.; Uchida, T.; Sunathvanichkul, T.; Nakagawa, T.; Masukata, H. Ordered Assembly of Sld3, GINS and Cdc45 Is Distinctly Regulated by DDK and CDK for Activation of Replication Origins. EMBO J. 2006, 25, 4663-4674. [CrossRef] [PubMed]

61. Deegan, T.D.; Yeeles, J.T.; Diffley, J.F. Phosphopeptide Binding by Sld3 Links Dbf4-Dependent Kinase to MCM Replicative Helicase Activation. EMBO J. 2016, 35, 961-973. [CrossRef] [PubMed]

62. Fang, D.; Cao, Q.; Lou, H. Sld3-MCM Interaction Facilitated by Dbf4-Dependent Kinase Defines an Essential Step in Eukaryotic DNA Replication Initiation. Front. Microbiol. 2016, 7, 885. [CrossRef] [PubMed]

63. Itou, H.; Muramatsu, S.; Shirakihara, Y.; Araki, H. Crystal Structure of the Homology Domain of the Eukaryotic DNA Replication Proteins Sld3/Treslin. Structure 2014, 22, 1341-1347. [CrossRef] [PubMed]

64. Bruck, I.; Kaplan, D.L. Conserved Mechanism for Coordinating Replication Fork Helicase Assembly with Phosphorylation of the Helicase. Proc. Natl. Acad. Sci. USA 2015, 112, 11223-11228. [CrossRef] [PubMed]

65. Hardy, C.F.; Sussel, L.; Shore, D. A RAP1-Interacting Protein Involved in Transcriptional Silencing and Telomere Length Regulation. Genes Dev. 1992, 6, 801-814. [CrossRef] [PubMed]

66. Lian, H.-Y.; Robertson, E.D.; Hiraga, S.; Alvino, G.M.; Collingwood, D.; McCune, H.J.; Sridhar, A.; Brewer, B.J.; Raghuraman, M.K.; Donaldson, A.D. The Effect of Ku on Telomere Replication Time Is Mediated by Telomere Length but Is Independent of Histone Tail Acetylation. Mol. Biol. Cell 2011, 22, 1753-1765. [CrossRef] [PubMed]

67. Cornacchia, D.; Dileep, V.; Quivy, J.-P.; Foti, R.; Tili, F.; Santarella-Mellwig, R.; Antony, C.; Almouzni, G.; Gilbert, D.M.; Buonomo, S.B.C. Mouse Rif1 Is a Key Regulator of the Replication-Timing Programme in Mammalian Cells. EMBO J. 2012, 31, 3678-3690. [CrossRef] [PubMed]

68. Hayano, M.; Kanoh, Y.; Matsumoto, S.; Renard-Guillet, C.; Shirahige, K.; Masai, H. Rif1 Is a Global Regulator of Timing of Replication Origin Firing in Fission Yeast. Genes Dev. 2012, 26, 137-150. [CrossRef] [PubMed]

69. Yamazaki, S.; Ishii, A.; Kanoh, Y.; Oda, M.; Nishito, Y.; Masai, H. Rif1 Regulates the Replication Timing Domains on the Human Genome. EMBO J. 2012, 31, 3667-3677. [CrossRef] [PubMed]

70. Foti, R.; Gnan, S.; Cornacchia, D.; Dileep, V.; Bulut-Karslioglu, A.; Diehl, S.; Buness, A.; Klein, F.A.; Huber, W.; Johnstone, E.; et al. Nuclear Architecture Organized by Rif1 Underpins the Replication-Timing Program. Mol. Cell 2016, 61, 260-273. [CrossRef] [PubMed]

71. Davé, A.; Cooley, C.; Garg, M.; Bianchi, A. Protein Phosphatase 1 Recruitment by Rif1 Regulates DNA Replication Origin Firing by Counteracting DDK Activity. Cell Rep. 2014, 7, 53-61. [CrossRef] [PubMed]

72. Wei, L.; Zhao, X. A New MCM Modification Cycle Regulates DNA Replication Initiation. Nat. Struct. Mol. Biol. 2016, 23, 209-216. [CrossRef] [PubMed]

73. Raghuraman, M.K.; Winzeler, E.A.; Collingwood, D.; Hunt, S.; Wodicka, L.; Conway, A.; Lockhart, D.J.; Davis, R.W.; Brewer, B.J.; Fangman, W.L. Replication Dynamics of the Yeast Genome. Science 2001, 294, 115-121. [CrossRef] [PubMed]

74. Kim, S.-M.; Dubey, D.D.; Huberman, J.A. Early-Replicating Heterochromatin. Genes Dev. 2003, 17, $330-335$. [CrossRef] [PubMed]

75. Koren, A.; Tsai, H.-J.; Tirosh, I.; Burrack, L.S.; Barkai, N.; Berman, J. Epigenetically-Inherited Centromere and Neocentromere DNA Replicates Earliest in S-Phase. PLoS Genet. 2010, 6, e1001068. [CrossRef] [PubMed] 
76. Müller, C.A.; Nieduszynski, C.A. Conservation of Replication Timing Reveals Global and Local Regulation of Replication Origin Activity. Genome Res. 2012, 22, 1953-1962. [CrossRef] [PubMed]

77. Tiengwe, C.; Marcello, L.; Farr, H.; Dickens, N.; Kelly, S.; Swiderski, M.; Vaughan, D.; Gull, K.; Barry, J.D.; Bell, S.D.; et al. Genome-Wide Analysis Reveals Extensive Functional Interaction between DNA Replication Initiation and Transcription in the Genome of Trypanosoma brucei. Cell Rep. 2012, 2, 185-197. [CrossRef] [PubMed]

78. Ahmad, K.; Henikoff, S. Centromeres Are Specialized Replication Domains in Heterochromatin. J. Cell Biol. 2001, 153, 101-110. [CrossRef] [PubMed]

79. Natsume, T.; Müller, C.A.; Katou, Y.; Retkute, R.; Gierliński, M.; Araki, H.; Blow, J.J.; Shirahige, K.; Nieduszynski, C.A.; Tanaka, T.U. Kinetochores Coordinate Pericentromeric Cohesion and Early DNA Replication by Cdc7-Dbf4 Kinase Recruitment. Mol. Cell 2013, 50, 661-674. [CrossRef] [PubMed]

80. Takahashi, T.S.; Basu, A.; Bermudez, V.; Hurwitz, J.; Walter, J.C. Cdc7-Drf1 Kinase Links Chromosome Cohesion to the Initiation of DNA Replication in Xenopus Egg Extracts. Genes Dev. 2008, 22, 1894-1905. [CrossRef] [PubMed]

81. Wu, K.Z.L.; Wang, G.-N.; Fitzgerald, J.; Quachthithu, H.; Rainey, M.D.; Cattaneo, A.; Bachi, A.; Santocanale, C. DDK Dependent Regulation of TOP2A at Centromeres Revealed by a Chemical Genetics Approach. Nucleic Acids Res. 2016, 44, 8786-8798. [CrossRef] [PubMed]

(C) 2016 by the authors; licensee MDPI, Basel, Switzerland. This article is an open access article distributed under the terms and conditions of the Creative Commons Attribution (CC-BY) license (http:/ / creativecommons.org/licenses/by/4.0/). 